Félix, D., Monteiro, D., Branco, J.M., Bologna, R., Feio, A. (2015) The role of temporary accommodation buildings for post-disaster housing reconstruction. Journal of Housing and the Built Environment 30 (4). pp 683-699. DOI 10.1007/s10901-014-9431-4

\title{
THE ROLE OF TEMPORARY ACCOMMODATION BUILDINGS FOR POST-DISASTER HOUSING RECONSTRUCTION
}

\section{Daniel Félix}

University Lusíada of Vila Nova Famalicão, CITAD

\section{Daniel Monteiro}

University Lusíada of Vila Nova Famalicão

\section{Jorge M. Branco}

University of Minho, ISISE

\section{Roberto Bologna}

University of Florence, Dept. of Architecture

\section{Artur Feio}

University Lusíada of Vila Nova Famalicão, CITAD

\section{CORRESPONDING AUTHOR:}

Daniel Félix

University Lusíada of Vila Nova Famalicão, Largo Tinoco de Sousa - 4760-108 VNF, Portugal

E-mail address:

ffelixdaniel@gmail.com

danielfelix@fam.ulusida.pt 


\title{
THE ROLE OF TEMPORARY ACCOMMODATION BUILDINGS FOR POST-DISASTER HOUSING RECONSTRUCTION
}

\begin{abstract}
The number of houses damaged or destroyed after disasters is frequently large, and re-housing of homeless people is one of the most important tasks of reconstruction programmes. Reconstruction works often last long and during that time, it is essential to provide victims with the minimum conditions to live with dignity, privacy, and protection. This research intends to demonstrate the crucial role of temporary accommodation buildings to provide spaces where people can live and gradually resume their life until they have a permanent house. The study also aims to identify the main problems of temporary accommodation strategies and to discuss some principles and guidelines in order to reach better design solutions. It is found that temporary accommodation is an issue that goes beyond the simple provision of buildings, since the whole space for temporary settlement is important. Likewise, temporary accommodation is a process that should start before a disaster occurs, as a preventive pre-planning. In spite of being temporary constructions, these housing buildings are one of the most important elements to provide in emergency scenarios, contributing for better recovery and reconstruction actions.
\end{abstract}

KEY WORDS: Destruction; Disasters; Homeless; Housing; Reconstruction; Sheltering; Temporary accommodation; Temporary buildings.

\section{INTRODUCTION}

The incidence of natural disasters has considerably increased during the last decades. Numerous buildings have suffered serious consequences that have frequently led to their total collapse. Housing buildings are extremely vulnerable and their destruction is one of the most visible effects after a disaster. As a consequence, most of the times post-disaster situations have a high number of homeless people in an urgent need for a place to live.

The scenario of destruction and the lack of essential goods provide all the conditions to increase the effects of the disaster and it is widely accepted that the impact of the event is directly related to the recovery and reconstruction capacity. The sooner the reconstruction starts the lower the future consequences will be (UNDRO, 1982). The whole recovery process is important, although the reconstruction of houses has a crucial relevance. A house is one of the most important needs for people and essential for their well-being, providing conditions to live with protection, security, comfort, and privacy. Thus, losing a house represents more than a physical deprivation, it is losing dignity, identity and privacy (Barakat, 2003). In a chaotic post-disaster situation, not only is a house a vital element to re-establish some normalcy in the life of the affected people, but also the house prevents the rising of deaths and the spread of diseases, once personal hygiene conditions and protection against external factors are ensured.

The difficult challenge in providing houses after disasters is the time needed to repair or rebuild the ones that were damaged, as well as to construct new buildings. Those works take time and in the meanwhile, it is imperative to develop architectural solutions to provide the affected people with temporary accommodation solutions. However, many programs of temporary accommodation after disasters have been criticized due to several problems and undesirable outcomes. 
This study aims to demonstrate the crucial role of temporary accommodation buildings during reconstruction programmes after disasters, identifying the common problems and suggesting guidelines to overcome them. Through this discussion, the present work intends to develop principles to improve the development of architectural designs for temporary accommodation solutions.

\section{METHODS}

Through a qualitative approach, this research uses literature review to discuss the main issues regarding temporary accommodation buildings for post-disaster reconstruction. Analysing theoretical studies and field reports that are available in the literature about the topic, this research discusses the role of post-disaster temporary accommodation buildings and tries to identify the common patterns, namely the strategies and solutions that have and have not succeeded, as well as the main reasons of success or failure. Then, these findings are used to develop guidelines to support and improve the development of post-disaster temporary accommodation buildings.

\section{WHAT IS TEMPORARY ACCOMMODATION?}

During post-disaster reconstruction programmes, providing temporary buildings for people inhabit is an essential priority. Between the aftermath of the disaster and the return to the repaired house, or the resettlement in a new one, lies a great amount of intermediate options. According to UNDRO (1982), there are eight basic types of post-disaster shelter provision: tents, imported designs and units, standard designs incorporating indigenous materials, temporary housing, the distribution of materials, core housing, hazard resistant housing, and accelerating the reconstruction of permanent housing.

The shelter strategies proposed by UNDRO seem to reflect what Quarantelli (1995) considers the variety of unclear and inconsistent ways the terms sheltering and housing are used in postdisaster reconstruction studies. Suggesting that sheltering indicates a place to stay during the immediate period after the disaster suspending daily activities, while housing involves the return to household responsibilities and daily routine, Quarantelli (1995) makes a distinction between those terms suggesting a definition of four distinct stages of post-disaster housing reconstruction:

a) Emergency shelter - a place where survivors stay for a short period of time during the height of the emergency, which can be in the house of a friend or in a public shelter;

b) Temporary shelter - used for an expected short stay, ideally no more than a few weeks after the disaster, this may be a tent, a public mass shelter, etc.;

c) Temporary housing - the place where the survivors can reside temporarily, usually planned for six months to three years, returning to their normal daily activities, and can take the form of a prefabricated house, a rented house, etc.;

d) Permanent housing - return to the rebuilt house or resettle in a new one to live permanently. In addition to the four terms presented above, Johnson (2002) proposes the term temporary accommodation referring to all different types of temporary lodging commonly used after disasters until the relocation in a permanent house. Therefore, temporary accommodation includes all the solutions used during the emergency shelter, temporary shelter, and temporary housing stages, see Figure 1. 


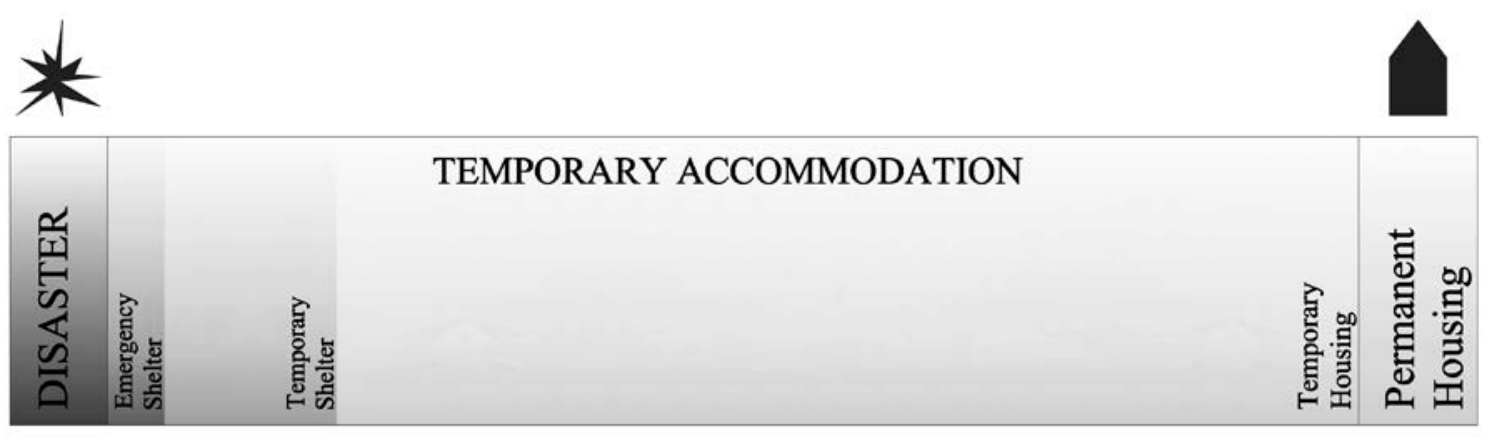

time

Figure 1 - Temporary accommodation phases during reconstruction programs (source: author production).

\section{THE ROLE OF TEMPORARY ACCOMMODATION}

After a disaster, people tend to be shocked, traumatized, and extremely worried about their future due to the losses of relatives and friends, and also because of the losses of their goods and belongings. Losing the house is one of the most important primary stress factors (Caia et al, 2010). Since reconstruction works often last long, temporary accommodation fills that period of time providing solutions that support vital functions such as protection, security, privacy and minimum comfort conditions (Kronenburg, 2009), helping to prevent the death of thousands of people in a second disaster (Renton and Palmer, 2005). This way, temporary accommodation actively contributes to help people overcoming the feeling of uncertainty caused by the hazard and gradually regain their life. Supplying a secure place for people to recover, temporary accommodation also contributes to create conditions for the success of the whole reconstruction programme, allowing adequate time for planning and carrying out the works.

Each type of temporary accommodation has different requirements and objectives according to its function as a part of the stages discussed previously. The complexity and capacity of the solution seem to improve according to the phase. The emergency stage presents simple structures while solutions with more capability and infrastructures are usually provided during the temporary stage.

\subsection{Emergency shelter}

Most of the times the emergency shelter phase does not need to construct or supply any kind of temporary building because it only refers to the aftermath of the disaster. Therefore, existing big spaces, such as schools or sport pavilions, are usually used. However, due to the needs for privacy and space delimitation, some simple solutions have been developed to improve the living conditions of victims, see Figure 2a. Likewise, some elementary designs have been presented to provide basic and quick shelter right after a disaster in exterior spaces, see Figure 2b. 


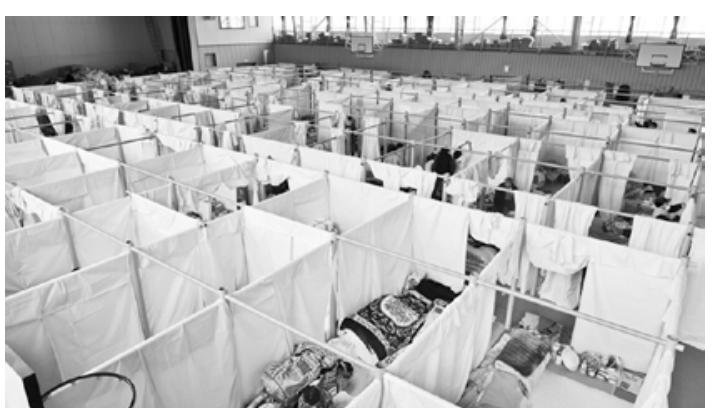

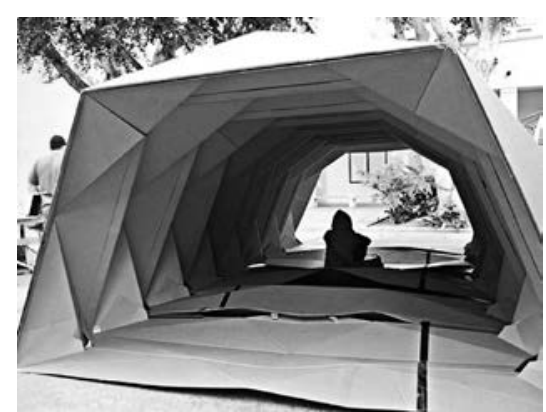

b

Figure 2 - Emergency shelters: (a) Paper Partition System 4 - Shigeru Ban Architects - used after the 2011 earthquake in Japan to provide shelter in gymnasiums before supplying temporary housing (source http://www.shigerubanarchitects.com); and (b) foldable and portable shelters - Tina Hovsepian -built from recycled cardboard and based on the principles of origami (source - http://inhabitat.com).

\subsection{Temporary shelter}

While staying in emergency shelters, people affected by disasters have protection and provision of minimum basic needs although they will certainly have few difficulties due to the lack of space. Temporary shelters protect people from external aggressions and simultaneously ensure some privacy to rest and recover in emotional terms, as well as space for simple daily activities and storage of belongings. These temporary buildings also provide the minimum own space that each one needs, as well as space for gathering family. Besides that, temporary shelters are essential to grant people the minimal life conditions while temporary housing stage is being planned and prepared.

Since these kinds of buildings are intended to be quickly available after a disaster, they tend to be smaller and made of lighter materials to facilitate their transportation and assembly, however these materials are intended to last long enough. According to Asefi and Sirius (2012), in terms of material, use and construction, there are two main types of shelters:

a) Shelters with transformable elements, that use flexible and rigid elements, see Figure 3a.

This kind of shelter is easy to carry and assemble, as well as lightweight. The tent is the most used type of temporary shelter (UNDRO, 1982; Hamilton, 2012);

b) Shelters with non-transformable elements, which use only rigid materials, see Figure 3b. Although these solutions are easy to assemble, the transportation tend to be complicated and delayed due to the higher weight.

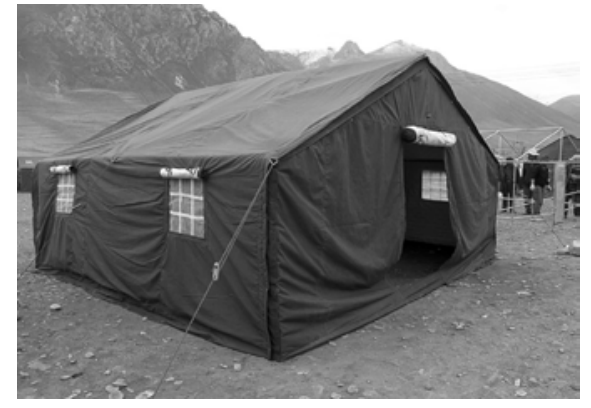

a

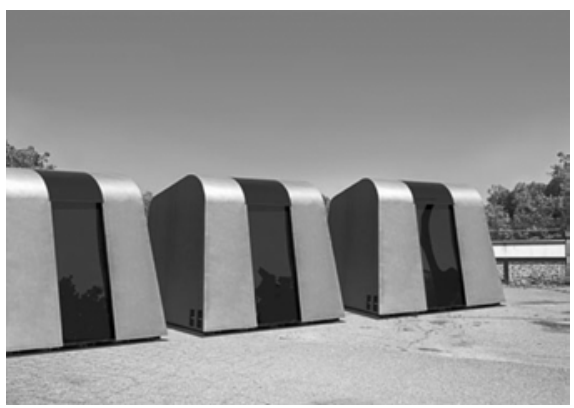

b

Figure 3 - Temporary shelters: (a) with transformable elements (source - http://sichuan-quake-relief.org/), and (b) with non-transformable elements (source - http://www.reactionhousingsystem.com/). 


\subsection{Temporary housing}

In spite of having their own space in temporary shelters, people cannot resume their daily life, so it is impracticable to stay longer in them. The next stage, temporary housing, seems to be the obvious solution to bridge over the time gap between temporary shelter and the conclusion of reconstruction works (Johnson et al, 2010). Temporary housing solutions have the necessary conditions and spaces to allow people to return to their normal activities such as cooking, housekeeping, working, socializing, attending school, etc. Thus, it is a crucial phase because it promotes the return to normalcy in a chaotic and uncertain post-disaster situation, being an essential step of reconstruction programmes (Johnson, 2007a). Two main groups of temporary housing solutions can be identified (Félix et al, 2013a):

a) Ready-made units, which are totally manufactured in factory, and then transported to their future place, which may require few simple assembly works in site, see Figure 4a;

b) Kit supplies, which consist on the provision of all the elements that constitute the building to be totally assembled in the site, see Figure $4 \mathrm{~b}$.

No matter the chosen model, temporary housing buildings tend to be similar to a permanent house, being bigger and more resistant than temporary shelters and providing essential infrastructures, such as water supply, drainage, electricity, etc.

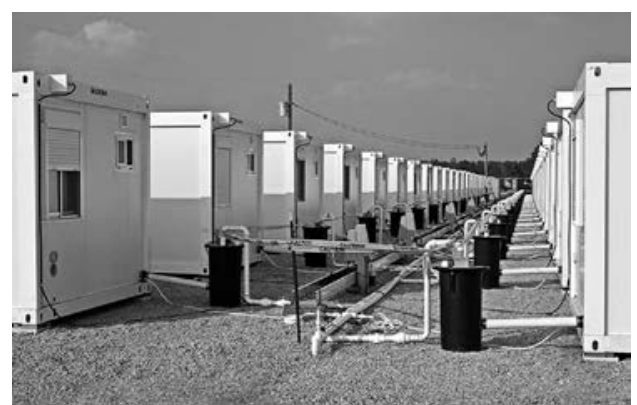

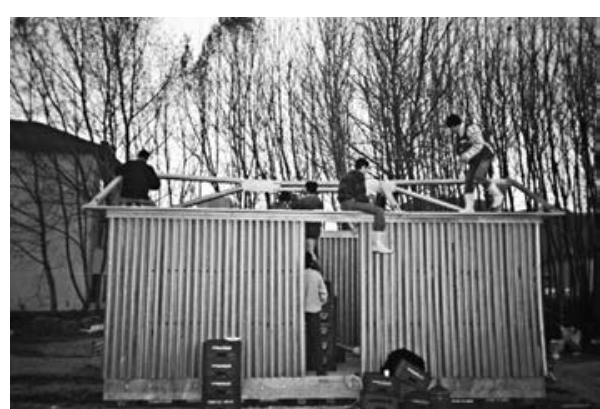

b

Figure 4 - Temporary housing: (a) ready-made solutions with complex systems to provide basic infrastructures (source - www.katrinadestruction.com), and (b) kit supplies, Paper Log Houses - Shigeru Ban Architects, being locally assembled (source - https://archnet.org).

\section{COMMON PROBLEMS OF TEMPORARY ACCOMMODATION BUILDINGS}

Numerous solutions and strategies have been developed and implemented over the last decades, yet some problems seem to persist and avoid solutions to reach more effective and successful outcomes (Kronenburg, 2009).

Designing a house is a complex task because it reflects and is simultaneously the result of the social, cultural, religious, political, economical, environmental, technical, and other interactions (UNDRO, 1982). A house is also a source of pride and cultural identity (Barakat, 2003), the space people inhabit and attribute a strong symbolism too. In disaster situations, the destruction leads to the loss of those symbolic references (Bedoya, 2004), and instead of trying to restore them, housing strategies followed after disasters often build alien environments, see Figure 5. The solutions implemented in order to temporary resettle people made homeless by disasters have frequently been inappropriate and culturally unacceptable (Gulahane and Gokhale, 2012). Due to that inadequacy, there are common situations of shelters and houses that were only used 
after many modifications made by users and cases of units that were never used (El-Masri and Kellett, 2001; Barenstein, 2006; Sener and Altum, 2009).

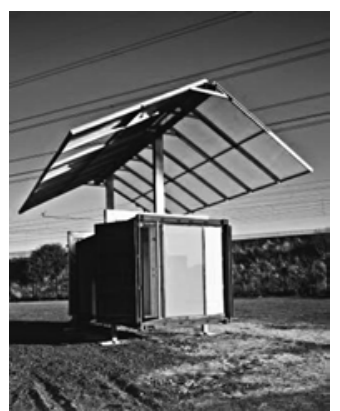

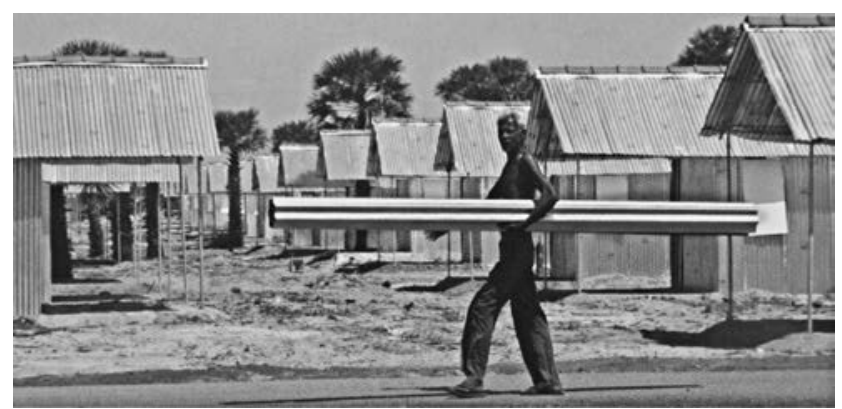

Figure 5 - Inadequate temporary accommodation buildings and settlements: (a) Future Shack , Sean godsell Architects, a building that seems to technological and expensive for post-disaster temporary accommodation (source - http://www.seangodsell.com), and (b) a locally and culturally inadequate temporary settlement, called by locals as ‘microwave ovens’ (source - D’Urzo, 2011).

The economical and environmental questions are also considerable problems of temporary accommodation solutions. The costs of these temporary buildings are usually high, which has been considered a waste of funds owing to the relation between the great investments needed to buy them and their short lifespan. That problem seems to be more criticized in the case of temporary housing (Johnson, 2007a, 2007b, 2008), since the cost of a temporary house can be the same as a permanent one (UNDRO, 1982) or even three times higher (Hadafi and Fallahi, 2010). This is a critical question because that overspending draws away resources that are crucial for the permanent reconstruction of houses (Johnson, 2007b).

In terms of environmental issues, temporary accommodation strategies have experienced problems with the future use of the units when they are no longer needed. Temporary accommodation units are frequently in good state of repair after their intended period of usage. However, most programmes for temporary accommodation have no plan for the great amount of vacant buildings, yet useable, and they are often simply dismantled without any concern for the future use of the resultant elements, which is an impressive waste of resources (Arslan and Cosgun, 2007). In addition, the site where the units were placed often becomes polluted because sometimes the infrastructures and foundations are not removed and the place is not cleaned in order to restore its original condition as in pre-disaster.

Those economical and environmental problems are more common in the temporary housing phase, probably because of its longer usage period, as well as the need for more infrastructure and resource consumption.

\section{HOW PROBLEMS APPEAR}

Most of the temporary accommodation problems are due to misunderstandings regarding the circumstances that people experience after a disaster (Kronenburg, 2009). Those problems previously identified happen mainly with the solutions applied by formal projects, which are the ones developed by governments, non-governmental organizations, international aid agencies, and similar. A considerable part of these solutions is not produced in the region of the disaster but in a different country, and so, solutions are usually developed by professionals and 
technicians that are not familiar with the local reality. Local people are rarely listened or consulted to identify their needs and expectations, and the cultural differences between the beneficiaries and the professionals may produce misunderstandings and inadequate solutions (UNDRO, 1982), being the result of what they consider the most appropriate given the limited resources available, but not what is suitable for people (Lizarralde and Davidson, 2006). As a result, the implemented designs have often led to culturally inadequate and locally inappropriate solutions (Félix et al, 2013b).

Additionally, most of those solutions are based on standardized, mass-produced, and prefabricated design. However, the concept of a standard architectural solution might not be appropriate because it ignores local context, climacteric conditions, variations in cultural values and house forms, variations in family size, and other issues (UNDRO, 1982). It seems that these designs emphasize the structural safety, fast production, and supplying speed, yet neglecting the real needs and expectations of victims.

Since the buildings are produced in a foreign country, they have to be imported and then transported to the site. That kind of procedure tend to increase the final price of the units because it includes the price of external production and the transport, not taking advantage of the local resources, such as materials and workforce. Besides being expensive, sometimes reaching two thirds of the cost of materials (Harris, 2011), transportation often takes time, which delays the delivery and distribution of the units, forcing the affected people to stay longer in critical conditions.

The nonexistence of pre-planning is another important factor that contributes to raise the problems of temporary accommodation. Post-disaster scenarios have the propitious conditions to result in inadequate solutions due to the urgency to develop solutions under high pressure and with lack of resources (Johnson, 2002). When there is no strategy pre-planned, the decisions tend to focus on the immediate needs, but the aim for quick results has not been satisfactory in a long-term. People are frequently forced to stay longer in temporary buildings and settlements. However, since these solutions are not planned for long periods of use, social problems, and environmental degradation of the built environment are likely to occur.

\section{PRINCIPLES TO IMPROVE TEMPORARY ACCOMMODATION SOLUTIONS}

The identification of the common problems, as well as their origin, opens space to the discussing of some principles that can improve the outcomes of temporary accommodation solutions. It seems that three main principles can be proposed: pre-planning, using local resources, and supplying more than just temporary accommodation units.

\subsection{Pre-planning}

Post-disaster situations have all the factors to result in wrong and unsuccessful strategies to rehouse homeless people: the scenario of destruction, people scared and extremely weak in psychological terms, lack of resources, people working under pressure, etc. Additionally, in the following weeks after the event, several institutional aid agencies and NGOs often arrive at the site and immediately start acting, although without satisfactory relation and coordination among them and with the local authorities. That lack of organization often gives rise to misunderstandings and wrong options, with different organizations working for the same purpose but in different directions. Due to that, those approaches have resulted in waste of resources and time that applied under a global strategy could result in more efficient reconstruction strategies. 
Particularly in the case of temporary accommodation, developing a strategic pre-plan has a crucial importance, as decisions may be best taken before the disaster (Gulahane and Gokhale, 2012). The problems of sustainability and cultural inadequacy previously discussed would be considerably reduced with a strategic pre-plan establishing beforehand the type of shelter or house and the places for temporary settlements, as well as the priorities, ways of action, principles, and rules to follow in case a disaster occurs.

In terms of temporary accommodation, a strategic pre-planning should consider the following issues to succeed:

a) Preparing an area with infrastructures beforehand for temporary settlements. Finding a secure site to settle the temporary accommodation buildings and installing the basic infrastructures needed, such as water supply, sanitation, electricity, etc., may become an arduous task to manage in a chaotic post-disaster scenario. On the other hand, establishing and preparing a secure place beforehand with the needed conditions to be used as a temporary settlement is a preventive action that provides for the success of the re-housing programme. In case of a disaster, victims could be quickly sheltered since everything would be ready to settle the temporary buildings. This already prepared place should not be seen as an area for emergencies, but as a public space that has all the infrastructures to be used as an emergency area. The site may be a garden, park, etc., which can be used by people for leisure and cultural activities during ordinary times, and used for temporary accommodation during crisis scenarios (Bologna, 2006). Therefore, having an already defined and prepared site for temporary settlements after disasters is a profitable way to offer public spaces for citizens and simultaneously be prepared for disasters and emergencies.

b) Forecasting. Having an idea about what could be the consequences of a disaster in terms of housing destruction, helps to predict the possible number of houses damaged or destroyed. Thus, it would be possible to anticipate the approximate amount of homeless people, and consequently an idea of the possible number of temporary units needed to re-house the victims. In the same way, it helps you have an idea of the resources, in terms of materials and investments, needed to provide temporary accommodation and for the reconstruction works. To reach that anticipation, it is necessary to make a complete assessment of the state of repair and structural safety of the existent buildings.

c) Making a wide and accurate characterization of the local context. A complete understanding of the cultural, social, economical, political, religious, climacteric, and many other local issues, is the key to design temporary accommodation buildings that fit local conditions and simultaneously may be sustainable. Identifying the forms of local housing and how they manifest the way of life of their inhabitants is the key to define temporary accommodation buildings that fit better the needs and expectations of people, respecting their culture, traditions, habits, and values. Thus, the local community has to be involved in the assessment of their own needs in order to guarantee that the temporary solutions will be acceptable for their lifestyle (UNDRO, 1982; Gulahane and Gokhale, 2012). The satisfaction of users is directly connected to the involvement in the assessment of needs and expectations (Lizarralde and Bouraoui, 2012).

The context characterization is also essential to assess the local capacity of reconstruction and re-housing. Depending on the resources and workforce available, the capacity may be higher or lower. A higher capacity means that reconstruction may be faster, and so, the time of dwelling in temporary accommodation is shorter. The opposite means that victims will 
stay longer in temporary units, which have to be resistant enough, and provide the minimum conditions to live in them with an acceptable level of comfort during that time. Likewise, the evaluation of the local workforce is important to know if people can actively participate in the works to erect temporary constructions, which influences the choice of the solution according to its assembly system and materials.

This data collection should be extensive and accurate since higher quality of basic information is more likely to be used to support prevention measures (Alexander, 2004), such as pre-planning.

d) Establishing the ways of action. With the data collected from the previous tasks, it is possible to establish the priorities in terms of works, the type of temporary accommodation solutions to use and their materials, how the units will be erected, and spatially organized on the ground. At the same time, the pre-plan should consider other issues, such as long-term outcomes for units and their sites (Johnson, 2007a).

The pre-planning may also determine actions to be taken in the existing buildings before a disaster occurs, such as consolidation, reinforcement, and maintenance. Those actions not only protect lives, but also decrease the level of destruction and the number of homeless people. This way pre-planning contributes to minimize the number of temporary accommodation units needed, improving the economical and sustainability issues.

Proactive measures prevent the need to make quick decisions after a disaster, since it diminishes the need to define strategies and take options under pressure. The pre-planning guides the actions and decisions under a coherent and locally based strategy. Even so, it has to be flexible enough to allow modifications and improvements according to a precise post-disaster situation.

\subsection{Using local resources}

The usage of local resources is undoubtedly a better option than the import of solutions (UNDRO, 1982; Barakat, 2003; Johnson, 2007a, 2007b; Lizarralde and Davidson, 2006; Dikmen et al, 2012). If available, local materials are probably culturally and socially more appropriate, as well as more economical, since they are familiar and avoid the high costs that transportation implies.

The use of local materials empowers the possibilities to involve local workforce in the erecting works, because local people are used to handle them. Local communities often have knowledge and construction skills (Bedoya, 2004), and previous studies have found that the first answers to the needs for shelter have been provided by survivors (UNDRO, 1982). Moreover, the active participation of the victims can be a useful way to restore the sense of pride and neighborhood relationship (Barakat, 2003), which is relevant after traumatic disaster events. However, not all kind of community participation can lead to positive outcomes, and so, it has to be locally determined (Davidson et al, 2007). Likewise, mass consumption of local materials can lead to sudden disruptions or severe environmental impacts such as deforestation (Shelter Centre, 2012).

In the same way, some indigenous and local construction techniques can be more resistant to disasters when compared to some modern building methods (Gulahane and Gokhale, 2012; Twigg, 2006), since such knowledge has been developed over the time and it is well adapted to the local environment (Boen and Pribadi, 2007; Shawn, 2009).

Even in a temporary location, housing seems to be evolutionary, developing according to the needs and possibilities of its users (Gulahane and Gokhale, 2012). Thus, users often make changes to the buildings, so they can address their needs and expectations, see Figure 6 (Sener 
and Altum, 2009). Likewise, in post-disaster scenarios the house is often a family workspace (Kellett and Tipple, 2000), and those modifications are essential to facilitate the creation of appropriate spaces for that. Using local materials and building technologies allow people to introduce modifications, which makes maintenance easier and more economical, in order to improve the long-term possibilities of the constructions. Despite the criticism to the new modern ways of production used to build temporary accommodation buildings, and the emphasis on the usage of local resources, it does not mean that innovation has no space in the development of temporary solutions. Properly used, that is to say culturally and locally integrated, innovation and technology may contribute in a useful manner to improve temporary accommodation solutions (Shaw, 2009; Davidson et al, 2008; Garofalo and Hill, 2008). Therefore, the design should balance a combination of technological and local ways of construction and materials (Félix et al, 2013c).

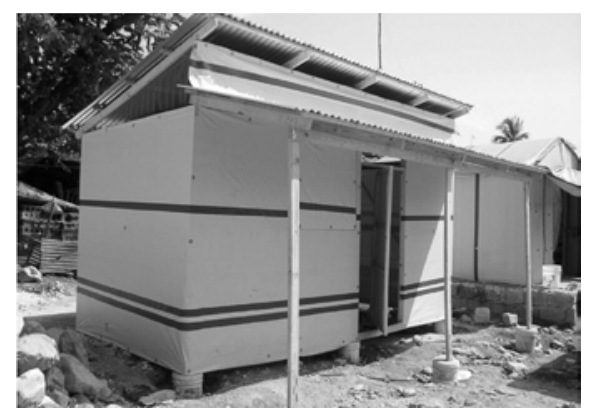

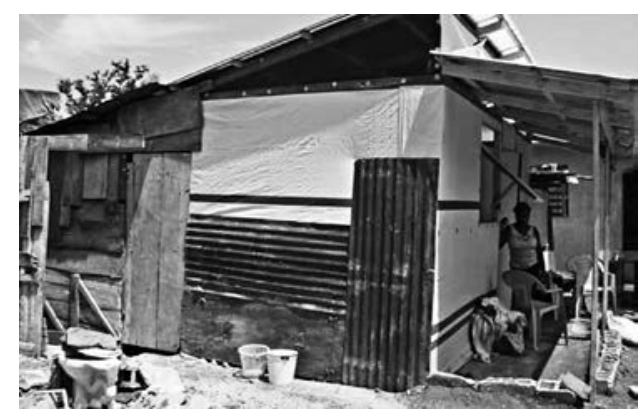

Figure 6 - Units modifications: (a) temporary housing unit before being used and (b) after the user modifies it (source - Saltzman et al, 2010).

\subsection{Supplying more than just temporary accommodation units}

A temporary shelter or house has to be more than a building to accommodate people while their damaged house is being built or rebuilt. Even in a temporary location, a house is more than the physical space that it encloses; it is an essential element for people to feel socially integrated and have a sense of belonging, being a source of pride and cultural identity (Barakat, 2003; Kronenburg, 2009). A house is a space for social, spiritual, and psychological needs (Hadafi and Fallahi, 2010), reflecting the personality of its users, who in turn, build part of their identity through their home (Kellett and Tipple, 2000). The most important thing for temporary accommodation solutions should be the people who will live in them, and not their technical aspects. Therefore, the buildings have to be designed from the point-of-view of the users rather than from functional and technical approaches (UNDRO, 1982), considering their daily activities, as well as the symbols and patterns adopted (Bedoya, 2004).

On the other hand, the exterior spaces surrounding the units have to be designed and well organized. Outdoor areas belonging to the units are relevant to create buffer zones between public spaces and the private domain, which is essential to create some privacy among neighbourhoods and encourage interaction (Caia et al, 2010). In the same way, exterior spaces can be used for working and cultivating activities, contributing for the improvement of families' economy.

The public spaces of the temporary settlement where the buildings are clustered also have an important role on the life quality of people while they are in a temporary accommodation. They 
are the support for social life, so designing them is designing the physic structure for social networks. The provision of public spaces may enable community to maintain their social ties as in pre-disaster, or even develop new ones, which is important during recovery (Johnson, 2007a). Thus, it is essential to design social spaces as squares, plazas, gardens, parks, etc. (Weia et al, 2012), so people can have places that create opportunities to meet and talk to others, socialize, organise activities for interaction between dwellers, and so on. Likewise, it is crucial to provide services and amenities to help people to regain their normal life activities. Depending on the scale of the temporary settlement, services such as schools, medical assistance points, post offices, etc., are essential to make those areas functional. Even in small settlements, it is extremely important to provide groceries, supermarkets, coffee shops, between others, because the normal use of these services introduces some sense of normalcy and routine, besides being helpful.

\section{RECOMMENDATIONS TO DESIGN TEMPORARY ACCOMMODATION BUILDINGS}

Based on the facts, problems, and principles discussed above, it seems that some recommendations to design temporary accommodation solutions can be suggested. One of the most important things after disasters is that temporary accommodation should be available as soon as possible. However, the urgency must not neglect crucial aspects to guarantee the adequacy and sustainability of the units, and the following recommendations seem to be helpful to reach that intention:

a) Designing for people. Solutions should be designed from users' point of view. It is imperative to shift the focus from the technical aspects of buildings to the development of more sensitive and friendly solutions, thinking more on creating 'homes' than designing shelters or houses.

b) Local-oriented design. The local forms of housing should be the starting point to develop the units (Barakat, 2003; Hamilton, 2012). The design should be as much as possible based on local materials and construction methods. It makes units more locally integrated and economical.

c) Simple construction systems. The works to erect the units should be as easier and faster as possible. Simple construction systems are preferred to gain speed, as well as to allow the involvement of local workforce. In the same way, it facilitates the dismantling process after their usage.

d) Easy to transport. When the local resources are scarce or non-existent and units have to be imported, the solution should be based on small and light elements to facilitate transportation, mainly to areas with difficult access.

e) Durability. The structural solution and materials must perform well during the intended period of use, and require few maintenance tasks.

f) Protection. The ephemeral condition of the building must be resistant enough to provide adequate protection from external factors, such as rain, snow, wind, high temperatures, etc.

g) Adequate dimensions. These must fit the needs of each family regarding space, enabling different layouts and configurations to allow variations according to the size of the families.

h) Comfort. Adequate conditions for privacy, indoor temperature, natural and artificial illumination, ventilation, etc.

i) Flexibility. Flexible solutions in terms of space and variety of configurations give victims the chance to use the unit as a multifunctional space, and also facilitate the transformations and 
modifications. It is also easier for users to personalize the unit, which can help them feel more attached to their spaces.

j) Outdoor spaces. Exterior spaces associated to the units are essential to provide privacy and promote opportunities to socialize, as well as to create working and cultivating zones, and possible expansions and additions.

k) Long-term options. Propose beforehand possible solutions for units after their intended period of use. Alternatives to reuse, for the same or a different purpose, and to recycle are extremely advantageous (Johnson, 2007a, 2007b, 2008; Arslan, 2007; Arslan and Cosgun, 2007; Arslan and Cosgun, 2008).

l) Non-pollutant solutions. Use more ecological and friendly construction techniques and materials to avoid environmental pollution.

\section{DISCUSSION}

The gap in between the loss of a house until permanent relocation usually results in temporary accommodation solutions. Thus, in terms of re-housing, one of the most important issues of reconstruction after disasters is the provision of temporary accommodation buildings, which has three distinct phases with different and specific objectives, improving the complexity and capability of the construction according to the phase.

In spite of being ephemeral buildings, the temporary term here implies a time of permanency, the period to return gradually to normalcy. While the emergency solutions support the basic needs to survive, the temporary solutions provide important conditions to return to normal life, even in a temporary location. This return to daily-life, most of the times, implies supplying not only temporary buildings, to provide each family with the necessary space and privacy, but also the infrastructures, facilities, services and exterior public spaces needed to support normal routines and social activities.

Despite the important role of these buildings, as well as, the great number of available solutions, some problems seem to persist. The strategies implemented have been culturally and locally inappropriate, and have resulted in unsustainable outcomes in economical and environmental terms. Those problems appear mainly due to misunderstandings and misconceptions about postdisaster situations and local context which, combined with the crisis, pressure, and lack of resources, have led to unsuccessful options and decisions.

The findings of this research indicate that more than developing new solutions and technological progresses, there is a need to change the way of approaching the problem:

a) Instead of developing solutions and strategies after the disaster occurs, it is crucial to be prepared and have strategies already developed beforehand;

b) Instead of focusing on imported and standard solutions, local resources and local oriented designs should be preferred;

c) Instead of a technocratic approach, it is vital to use more sensitive and people-oriented strategies.

Since an increase of disasters, due to hazards, is expected, temporary accommodation will certainly remain a central issue in reconstruction programmes, and this research intend be a useful resource to develop and design better solutions and strategies.

\section{ACKNOWLEDGMENT}

The first author gratefully acknowledges the financial support of Fundação para a Ciência e a Tecnologia, FCT, through grant SFRH / BD / 73853 / 2010 


\section{CITED WORKS}

Alexander, D. (2004). Planning for post-disaster reconstruction. 2004 International Conference and Student Competition on post-disaster reconstruction "Planning for reconstruction" Coventry, UK, April 22-23, 2004. Available online at: http://www.grif.umontreal.ca/pages/papers2004/Paper\%20-\%20Alexander\%20D.pdf Accessed in 01-06-2011.

Arslan, H. (2007). Re-design, re-use and recycle of temporary houses. Building and Environment , 42, 400-406.

Arslan, H., \& Cosgun, N. (2007). The evaluation of temporary earthquake houses dismantling process in the context of building waste management. International earthquake symposium. Kocaeli, Turkey.

Arslan, H., \& Cosgun, N. (2008). Reuse and recycle potentials of the temporary houses after occupancy:example of Duzce, Turkey. Building and Environment 43 , 702-709.

Asefi, M., Sirus, F. A. (2012). Transformable Shelter: Evaluation and New Architectural Design Proposals. Procedia - Social and Behavioral Sciences 51, 961 - 966.

Barakat, S. (2003). Housing Reconstruction after conflict and disaster. London: Overseas Development Institute.

Barenstein, J. D. (2006). Housing reconstruction in post-earthquake Gujarat: a comparative analysis. Overseas development institute (ODI). Humanitarian practice network (HPN).

Bedoya, F. G. (2004). Hábitat transitorio y vivienda para emergencias. Tabula Rasa. , 145-166.

Boen, Teddy, \& Pribadi, K. S. (2007). Engineering the non-engineered houses for better earthquake resistance in Indonesia. Proceedings of the DRH Contents Meeting-EDMNIED, Kobe, Japan, Availableat: http://drh.edm.bosai.go.jp/files/6cc5597e09050a9b482d9f257c5f256ec28f6e50/7_PT8_P.pdf

Bologna, R. (2006). Strategic planning of emergency areas for transitional settlement. 2006 International Conference and Student Competition on post-disaster reconstruction "Meeting stakeholder interests" Florence, Italy, May 1719, 2006. Available online at: http://www.grif.umontreal.ca/pages/BOLOGNA_Roberto.pdf Accessed in 04-102012.

Caia, G., Ventimiglia, F., Maass, A. (2010). Container vs. dacha: The psychological effects of temporary housing characteristics on earthquake survivors. Journal of Environmental Psychology 30, 60-66.

Davidson, C. H., Johnson, C., Lizarralde, G., Dikmen, N., \& Sliwinski, A. (2007). Truths and myths about community participation in post-disaster housing projects. Habitat International , 100-115.

Davidson, C., Lizarralde, G., \& Johnson, C. (2008). Myths and Realities of Prefabrication for Post-Disaster Reconstruction. 4th International i-Rec Conference 2008 - Building resilience: achieving effective post-disaster reconstruction. Christchurch, New Zealand.

Dikmen, N., Elias-Ozkan, S. T., \& Davidson, C. (2012). Comparison of post-disaster housing procurement methods in rural areas of Turkey. Open House International, 37, 28-39.

D’Urzo, S. (2011). News from the teardrop island. In M. J. Aquilino, Beyond Shelter. Architecture for Crisis (pp. 1223). London: Thames \& Hudson.

Félix, D.; Branco, J. M.; Feio, A. (2013a). Temporary housing after disasters: A state of the art survey. Habitat International 40, 136-141.

Félix, D.; Branco, J. M.; Feio, A. (2013b). Guidelines to Improve Sustainability and Cultural Integration of Temporary Housing Units. Conference proceedings. 6th international i-Rec conference; 26-30 May 2013; Ascona, Switzerland.

Félix, D; Feio, A.; Branco, J. M.; Machado, J. S. (2013c). The role of spontaneous construction for post-disaster housing. In: Structures and Architecture: Concepts, Applications and Challenges (pp. 937-944) - Cruz (ed), Taylor \& Francis Group, London.

El-Masri, S., \& Kellett, P. (2001). Post-war reconstruction. Participatory approaches to rebuilding the damaged villages of Leabanon: a case study of al-Burjain. Habitat International 25, 535-557.

Garofalo, L., \& Hill, D. (2008). Prefabricated Recovery: Post-Disaster Housing Component Production and Delivery. Without a Hitch - New Directions in Prefabricated Architecture, (pp. 64 - 71). Massachusetts. 
Gulahane, K. \& Gokhale, V.A. (2012). Design criteria for temporary shelters for disaster mitigation in India. In Lizarralde, G., Jigyasu, R., Vasavada, R., Havelka, S., Duyne Barenstein, J. (eds.). Participatory design and appropriate technology for disaster reconstruction. Conference proceedings. 2010 international i-Rec conference.

Hadafi, F., \& Fallahi, A. (2010). Temporary Housing Respond to Disasters in Developing Countries- Case Study: Iran-Ardabil and Lorestan Province Earthquakes. World Academy of Science, Engineering and Technology , 66, 1536-1542.

Hamilton, N. (2012). Post-disaster shelter: A studio-based response to emergency shelter in natural disaster zones. Sustainable Futures: Architecture and Urbanism in the Global South, Kampala, Uganda, 27 - 30 June 2012.

Harris, V. L. (2011). The architecture of risk. In M. J. Aquilino, Beyond Shelter. Architecture for Crisis (pp. 12-23). London: Thames \& Hudson.

Johnson, C. (2002). What's the big deal about temporary housing? Planning considerations for temporary accomodation after disasters: example of the 1999 turkish earthquakes. 2002 TIEMS Disaster Management Conference. Waterloo.

Johnson, C. (2007a). Strategic planning for post-disaster temporary housing. Disasters 31, 435-458.

Johnson, C. (2007b). Impacts of prefabricated temporary housing after disasters: 1999 earthquakes in Turkey. Habitat International 31, 36-52.

Johnson, C. (2008). Strategies for the Reuse of Temporary Housing. In I. a. Ruby, Urban Transformation (p. 323 a 331). Ruby Press: Berlim.

Johnson, C., Lizarralde, G. \& Davidson, C. (2010). A systems view of temporary housing projects in post-disaster reconstruction. Construction Management and Economics, 24:4, 367-378

Kellett, P., \& Tipple, A. G. (2000). The home as workplace: a study of income-generating activities within the domestic setting. Environment \& Urbanization , 12, 203-214.

Kronenburg, R. H. (2009). Mobile and flexible architecture: solutions for shelter and rebuilding in post-flood disaster situations. blue in architecture 09_ Proceedings_IUAV Digital Library.

Lizarralde, G., \& Davidson, C. (2006). “Learning from the poor”. In D. Alexander, Post-disaster reconstruction: Meeting stakeholders’ interest. Florença: Università degli studdi.

Lizarralde, G. \& Bouraoui, D. (2012). User’s participation and satisfaction in post-disaster reconstruction. In Lizarralde, G., Jigyasu, R., Vasavada, R., Havelka, S., Duyne Barenstein, J. (eds.). Participatory design and appropriate technology for disaster reconstruction. Conference proceedings. 2010 international i-Rec conference. Ahmedabad, India. Montreal: Groupe de recherche IF, GRIF, Université de Montréal.

Quarantelli, E. L. (1995). Patterns of sheltering and housing in US disasters. Disaster Prevention and management , 4, 43-53.

Renton, A., and Palmer, R. (2005). A place to stay, a place to live. Oxfam Briefing Note.

Saltzman, A., Speziale, C., Cesal, E., Arnold, H., Kernizan, S. (2010). Transitional to What? Available at: http://openarchitecturenetwork.org/projects/transitional_to_what (Accessed 17 March 2012).

Sener, S. M., and Altum, M. C. (2009). Design of a post disaster temporary shelter unit. A|Z ITU Journal of the Faculty of Architecture , 6, 58-74.

Shaw, R. (2009). Indigenous knowledge: disaster risk reduction, policy note. http://www.unisdr.org/we/inform/publications/8853 (Accessed 7 January 2012).

Shelter Centre (2012). Transitional shelter guidelines. Available at: www.sheltercentre.org/library 
Twigg, J. (2006). Technology, Post-Disaster Housing Reconstruction And Livelihood Security. (B. H. Centre, Ed.) Disaster Studies Working Paper No.15 .

UNDRO, (1982). Shelter after Disaster: Guidelines for Assistance. New York: United Nations.

Weia, L.; Lib, W.; Lia, K.; Liu, H.; Cheng, L. (2012). Decision Support for Urban Shelter Locations Based on Covering Model. Procedia Engineering 43, 59 - 64 . 